\title{
Ganglioside-liposome immunoassay for the detection of botulinum toxin
}

Received: 17 August 2003 / Revised: 17 October 2003 / Accepted: 22 October 2003 / Published online: 13 November 2003

(C) Springer-Verlag 2003

\begin{abstract}
A rapid and highly sensitive receptor immunoassay for botulinum toxin (BT) has been developed using ganglioside-incorporated liposomes. Botulism outbreaks are relatively rare, but their results can be very severe, usually leading to death from respiratory failure. To exert their toxicity, the biological toxins must first bind to receptors on the cell surface, and the trisialoganglioside GT1b has been identified as the cell receptor for BT. Therefore, in this study, GT1b was used to prepare the ganglioside-liposomes by spontaneous insertion into the phospholipid bilayer. In a sandwich-based, hybrid receptor immunoassay, BT is detected as a colored band on a nitrocellulose membrane strip, where BT bound to the GT1b-liposomes are captured by anti-BT antibodies immobilized in a band across the strip. The intensity of the colored band can be visually estimated, or measured by densitometry using computer software. The limit of detection (LOD) for BT in the lateral-flow assay system was $15 \mathrm{pg} \mathrm{mL}^{-1}$, which is comparable to the limits of detection achieved with the most sensitive assays previously reported. However, this rapid assay can be completed in less than $20 \mathrm{~min}$. These results demonstrate that the sandwich assay using GT1b-liposomes for detection of BT is rapid and very sensitive, suggesting the possibility for detecting BT in field screening, simply and reliably, without the need for complex instrumentation.
\end{abstract}

Keywords Botulinum toxin - Ganglioside - Liposomes · Ganglioside-liposomes · Immunoliposomes $\cdot$ Receptor immunoassay

\section{Introduction}

Biological toxins, viruses, and hormones must first bind to cell surface receptors in order to act inside the cells. Af-

S. Ahn-Yoon · T. R. DeCory · R. A. Durst ( Department of Food Science and Technology,

Bioanalytical Research Laboratory, Cornell University,

Geneva, New York 14456-0462, USA

e-mail:rad2@cornell.edu ter binding to the receptors, these biologically active molecules penetrate through the cell membrane, usually via endocytosis, and then exert their activity inside the cell. Carbohydrates, existing as glycolipids or glycoproteins on the cell surface, have long been implicated as major receptors for biological toxins [1] and as receptors for hormones and other small molecules. Gangliosides, sialic acidcontaining glycosphingolipids, are present in the plasma membranes of most vertebrate cells. The various functions of gangliosides have been studied, including their use as receptors for biological toxins [2, 3]. Since van Heyningen et al. reported that brain gangliosides bound and deactivated cholera toxin [4], the toxin deactivation effect of gangliosides has been studied with other toxins such as botulinum toxin [5] and tetanus toxin [6], which also suggested the function of gangliosides as toxin receptors. Gangliosides contain both hydrophilic and hydrophobic regions and carry a negative charge. The hydrophobic portion, ceramide, consists of a long-chain fatty acid linked to the amino alcohol sphingosine through an amide bond. The hydrophilic carbohydrate moiety is composed of hexoses, $\mathrm{N}$-acetylated hexosamines, and at least one sialic acid molecule. In the membrane, the ceramide portion is imbedded in the lipid bilayer, while the hydrophilic oligosaccharide chain is exposed to the outer environment [7]. This structure makes gangliosides well suited as a surface receptor for toxins. The structure of trisialoganglioside GT1b is shown in Fig. 1. As toxin receptors, gangliosides have been used in model membrane systems where the gangliosides were incorporated into liposome bilayers or lipid monolayers. Since gangliosides are natural cell membrane receptors, these ganglioside-incorporated liposomes can be a useful biomimetic model system to study the interaction between biological toxins and cell-surface gangliosides. Improved techniques to prepare ganglioside-liposomes have also been applied to the development of toxin detection assays that take advantage of the strong and specific interactions between toxins and gangliosides $[8,9,10]$.

Liposomes, spherical vesicles composed of a phospholipid bilayer surrounding an aqueous cavity, were originally 


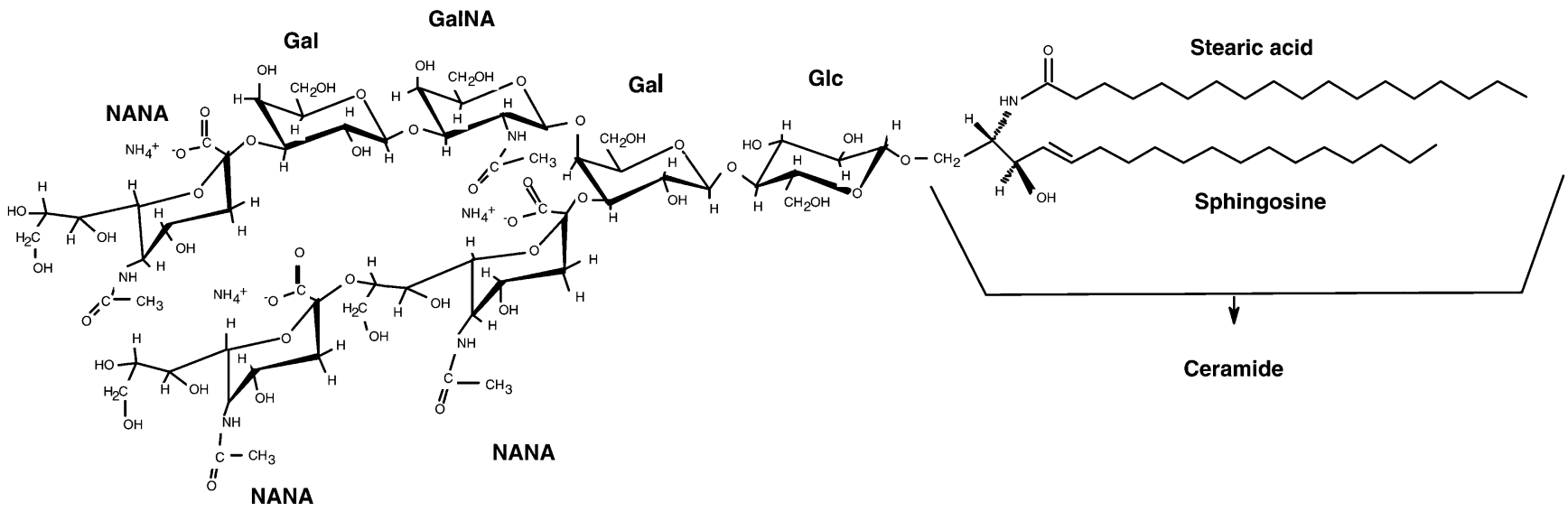

Fig. 1 Structure of the trisialoganglioside GT1b, which is one of the natural receptors for botulinum neurotoxin. Abbreviations: Glc, glucose; Gal, galactose; GalNAc, $N$-acetylgalactosamine; NANA, $N$-acetylneuraminic acid (sialic acid)

developed to study cell membranes. However, because of their ability to carry various water-soluble agents in their aqueous cavity, liposomes have been used in clinical diagnostics, drug delivery, and even in the cosmetics and food industries [11]. The use of liposomes in diagnostics has several advantages over enzyme-linked assays. Liposomes have the sites for ligands exposed on their surface and relatively large volumes for containing dye or other markers in their cavity, thus providing greatly enhanced signals. Liposomes utilized in sandwich assay detection systems mostly exist as immunoliposomes with antibodies on their surface, or as nucleic acid-tagged liposomes. Despite having specificity and strong affinity for biological toxins comparable to those of antibodies, gangliosides have not been widely used as receptors in liposome-based assays until recently. Ganglioside-incorporated liposomes have advantages over immunoliposomes because of the amphiphilicity of the gangliosides. Gangliosides contain the hydrophobic ceramide, which can be spontaneously incorporated into a lipid bilayer structure, while antibodies need several chemical steps for covalent conjugation to the liposome structure.

Botulinum neurotoxin (BT) produced by Clostridium botulinum is the most toxic substance known: as little as $0.05-0.1 \mu \mathrm{g}$ is a lethal dose in humans. Patients with botulism show neurological symptoms of flaccid muscular paralysis, with death resulting from respiratory failure if left untreated. In addition, the high probability of bioterrorists using biological toxins as agents of mass destruction, makes these toxins of even more serious concern [12]. Therefore, the development of rapid and sensitive detection methods for BT is urgently needed. At present, the mouse bioassay is the commonly accepted "gold-standard" method for the detection of BT [13]. Although it is highly sensitive, with a detection limit of $10-20 \mathrm{pg} \mathrm{mL}^{-1}$, the mouse bioassay is costly, time-consuming, and requires the use of animals. To date, several detection methods have been developed for BT as alternatives to the mouse bioassay: immunoassays, enzyme activity-based assays, and polymerase chain reaction (PCR)-based assays $[14,15,16$, 17]. In this study, BT was detected using gangliosideliposomes containing the intensely red sulforhodamine $\mathrm{B}$ (SRB) dye as the visual marker, and the trisialoganglioside GT1b receptor for BT was used for the preparation of the liposomes. Anti-BT antibodies were immobilized in narrow zones on plastic-backed nitrocellulose (NC) membrane sheets, which were then cut into test strips. In this sandwich assay system, BT was first bound to the GT1b on the liposomes and these were then captured by the antibodies in the analytical zone during capillary migration through the test strip. The presence of BT was observed as a colored band in the analytical zone on the strip. The intensity of the dye color in the band was measured either by visual estimation or by densitometry utilizing a computer scanner. As described below, in addition to its speed and specificity, the method has very high sensitivity, comparable to ELISA and the mouse bioassay, thereby providing a promising alternative detection approach.

\section{Materials and methods}

Materials

Dipalmitoyl phosphatidylcholine (DPPC), dipalmitoyl phosphatidylethanolamine (DPPE), and dipalmitoyl phosphatidylglycerol (DPPG) were purchased from Avanti Polar Lipids, Inc. (Alabaster, AL). $N$-( $\kappa$-maleimidoundecanoyloxy)sulfosuccinimide ester (sulfoKMUS), $N$-succinimidyl-S-acetylthiopropionate (SATA), hydroxylamine hydrochloride, and $N$-ethylmaleimide were purchased from Pierce (Rockford, IL). Trisialoganglioside (GT1b), sulforhodamine B (SRB), cholesterol, $N$-acetylneuraminic acid (NANA), and all other chemicals were purchased from Sigma Chemical Co. (St. Louis, MO). To avoid biological hazards, commercialized toxin subunits or toxoids (formaldehyde-inactivated toxins) were used, if available, in this study. Botulinum neurotoxin type A heavy chain, tetanus toxoid, diphtheria toxoid, and Escherichia coli heat-stable toxin (STa) were obtained from List Biological Laboratories, Inc. (Campbell, CA). Cholera toxin B subunit was purchased from Sigma Chemical Co. Affinity-purified rabbit polyclonal antibodies to botulinum toxin subtype A were purchased from Biogenesis (Poole, England). Nitrocellulose (NC) membranes with plastic backing (10- $\mu \mathrm{m}$ pore size) were obtained from Millipore (Bedford, MA). Polycarbonate (PC) filter membranes of $0.2-\mu \mathrm{m}$ pore size came from Whatman International Ltd. (Maidstone, England). The STa used in this study is an intact toxin, so it requires handling precautions. Appropriate laboratory attire should be worn, including a lab coat, gloves, and safety glasses. In case of exposure, the area of the 
body that comes into contact with STa should be washed thoroughly. STa can be inactivated by $0.04 \mathrm{mM}$ dithiothreitol or $0.1 \mathrm{M}$ $\beta$-mercaptoethanol. STa-contaminated materials can be inactivated by autoclaving at $121^{\circ} \mathrm{C}$ and $15 \mathrm{psi}$.

\section{Preparation of GT1b-liposomes}

GT1b-liposomes were prepared by the extrusion method, after repetitive freeze-thaw cycles [18], from a mixture of DPPC, DPPG, cholesterol, and GT1b in a molar ratio of 40.3:4.2:40.9:1.3. An 86.7- $\mu$ mol aliquot of the lipid mixture was completely dissolved in a $100-\mathrm{mL}$ round-bottom flask by swirling in $7 \mathrm{~mL}$ of a chloroform/methanol mixture $(6: 1, \mathrm{v} / \mathrm{v})$. The dissolved lipid mixture was dried by evaporation under vacuum on a rotary evaporator to form a thin lipid film on the flask wall. Four $\mathrm{mL}$ of a $150 \mathrm{mM}$ aqueous SRB solution, in $20 \mathrm{mM}$ HEPES buffer ( $\mathrm{pH} 7.5$ ) containing $0.01 \%$ sodium azide, were added to the dry lipid mixture. After gentle swirling, 5 cycles of freezing and thawing were performed, by alternating placement of the flask in a dry ice/acetone bath and a $50^{\circ} \mathrm{C}$ water bath. The hydrated liposomes were extruded through a $0.2-\mu \mathrm{m}$ pore size PC filter membrane using a mini-extruder (Avanti Polar Lipids, Inc.). The resulting liposomes were gel-filtered through a $1.5 \times 25 \mathrm{~cm}$ Sephadex G-50 column to remove unencapsulated dye.

The phospholipid concentration in the resulting liposomes was determined by quantitation of phosphorus using Bartlett's phosphorus assay [19]. The mean diameter of the liposomes was measured by laser-diffraction particle-size analysis with an LS particle-size analyzer (Coulter Scientific Instruments, Hialeah, FL). The ganglioside concentration in the liposomes was quantified by the method of Hikita et al. [20] using NANA as the standard. Liposome concentration, receptor concentration and the number of SRB molecules per liposome were determined as described previously [21].

Preparation of immunoliposomes

Preparation of DPPE-ATA

For conjugation of antibodies to liposomes, DPPE-ATA was prepared from DPPE and a thiolating reagent, SATA (21). DPPE $(7.2 \mu \mathrm{mol})$ was dissolved in $1 \mathrm{~mL}$ of $0.7 \%(\mathrm{v} / \mathrm{v})$ triethylamine in chloroform. SATA $(14.3 \mu \mathrm{mol})$ was added to the DPPE solution and sonicated for 1 min under nitrogen gas. The flask containing the mixture was capped and stirred for $20 \mathrm{~min}$ at room temperature. Addition of $3 \mathrm{~mL}$ of chloroform followed by evaporation was repeated until all traces of triethylamine were completely removed. The final product was dissolved in $1 \mathrm{~mL}$ of chloroform.

\section{Preparation of liposomes}

Liposomes were prepared by the extrusion method described above. For the immunoliposomes, DPPE-ATA $(3.6 \mu \mathrm{mol})$ was used in place of GT1b. Hydroxylamine solution $(0.5 \mathrm{M}$ hydroxylamine, $25 \mathrm{mM}$ EDTA in 0.1 M HEPES buffer, $\mathrm{pH} 7.5$ ) was added to the final liposome solution $(1: 10, \mathrm{v} / \mathrm{v})$ and the mixture was incubated in the dark for $2 \mathrm{~h}$ at room temperature.

\section{Modification of antibodies for conjugation}

Polyclonal antibodies to botulinum subtype A were dialyzed overnight against PBS (pH 7.4), containing $1 \mathrm{mM}$ ethylenediaminetetraacetic acid (EDTA) and $0.01 \%$ sodium azide. Sulfo-KMUS was added to the dialyzed antibodies at a molar ratio of 15:1 (sulfoKMUS:antibody), and the mixture was incubated with shaking for $3 \mathrm{~h}$ at room temperature in the dark. The reaction was stopped by adding $0.5 \mathrm{M}$ Tris $(\mathrm{pH} 7.8)$ at 20 times the molar ratio of the sulfoKMUS used. The reaction mixture was incubated for an additional $15 \mathrm{~min}$ at room temperature and then dialyzed in a DispoDialyzer (molecular weight cut-off 15,000, Spectrum Lab. Inc., Rancho Dominguez, CA) against Tris-buffered saline (TBS, pH 7.4) containing $0.01 \%$ sodium azide.

\section{Conjugation of maleimide-derivatized antibodies to liposomes}

Conjugation was achieved by incubating derivatized antibodies with thiolated liposomes for $3.5 \mathrm{~h}$ at room temperature and then overnight at $4{ }^{\circ} \mathrm{C}$. The reaction was carried out in the dark under nitrogen gas. After the incubation, the immunoliposomes were treated with $100 \mathrm{mM} N$-ethylmaleimide in PBS (pH 7.4) for $30 \mathrm{~min}$ at room temperature to quench the remaining thiol groups and then filtered through a $1.5 \times 17 \mathrm{~cm}$ Sepharose CL-4B column, equilibrated with TBS containing $0.01 \%$ sodium azide, to remove unconjugated antibodies.
Fig. 2 The test strip assay format. The BT in the reaction mixture binds to the gangliosides on the liposome surface. The BT-GT1b-liposome complex migrates through the nitrocellulose test strip by capillary action until it reaches the analytical zone, where toxins in the complexes are captured by immobilized antibodies. This binding is shown as a dark band on the test strip

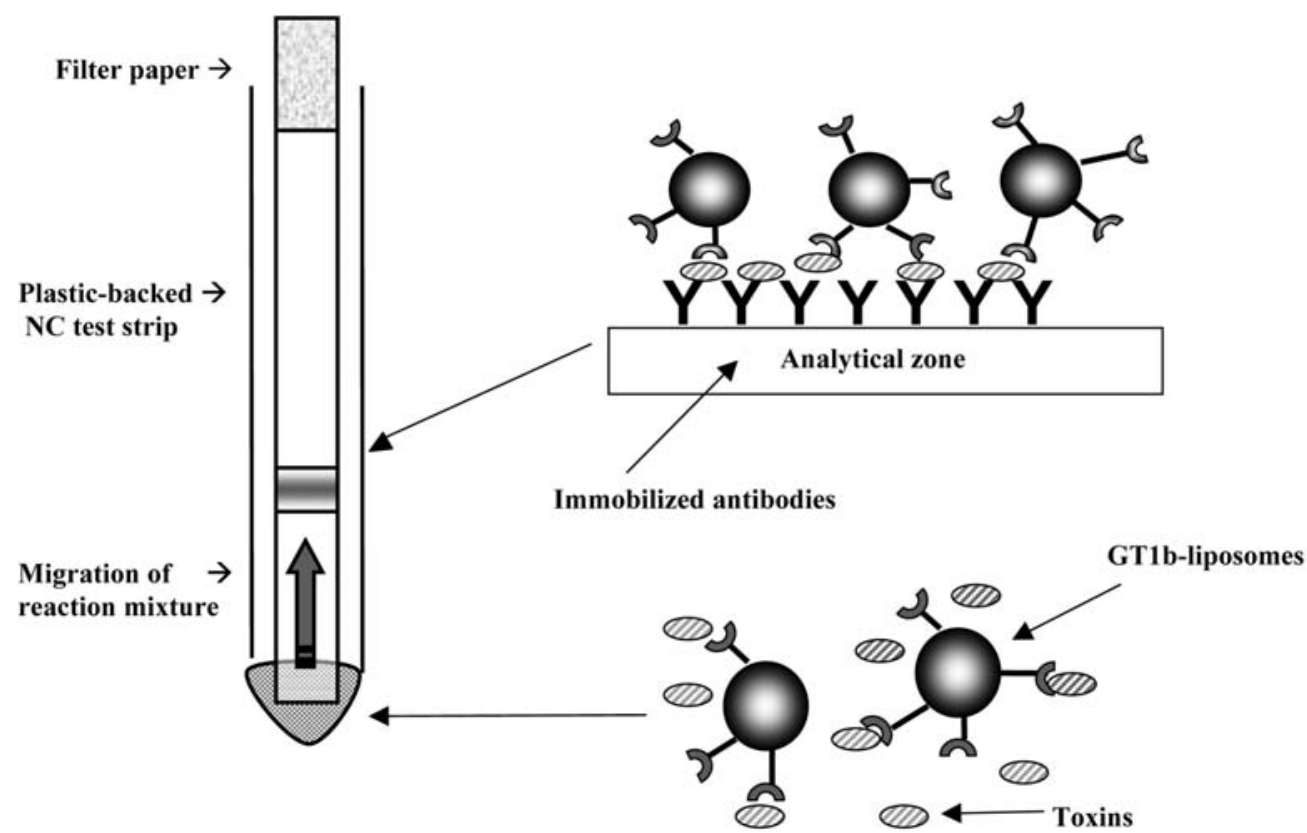


Preparation of test strips

Test strips were prepared as reported previously [21], with modifications. Plastic-backed NC membrane sheet was cut to the desired size $(20 \times 5 \mathrm{~cm}$ or $20 \times 8 \mathrm{~cm})$, pre-wetted with $10 \%(\mathrm{v} / \mathrm{v})$ methanol in phosphate-buffered saline (PBS, $\mathrm{pH} 7.4$ ) containing $0.01 \%$ sodium azide, and dried under vacuum at room temperature. Antibodies to botulinum neurotoxin subtype A (concentration of $1 \mathrm{mg} \mathrm{mL}^{-1}$ ) in PBS were applied to the analytical zone (approximately $2 \mathrm{~cm}$ from one end of the membrane) of the NC membranes using a Linomat IV TLC Sampler (Camag Scientific, Wrightsville Beach, NC). The antibody-immobilized membranes were dried for $1.5 \mathrm{~h}$ at room temperature, then incubated in the blocking solution containing $2 \%$ polyvinylpyrrolidone (PVP), $0.01 \%$ gelatin, $0.002 \%$ Tween 20 in PBS, for $1 \mathrm{~h}$ with constant shaking, and dried overnight under vacuum at room temperature. After drying, the membranes were cut into test strips $(5 \times 50 \mathrm{~mm}$ or $5 \times 80 \mathrm{~mm})$ and a filter paper pad was attached to the top of the test strip to provide additional absorbency for the migration process.

\section{Assay formats}

The assay was performed by adding $60 \mu \mathrm{L}$ of GT1b-liposome stock solution, diluted with TBS, to $40 \mu \mathrm{L}$ of the sample in glass test tubes $(10 \times 75 \mathrm{~mm})$. The total volume of the reaction mixture was $100 \mu \mathrm{L}$. After the contents were mixed briefly by swirling, the test strip was inserted into the mixture and left in the tube until all of the mixture solution was drawn from the bottom of the test tube. This capillary migration process took approximately $15-20 \mathrm{~min}$. The assay format is depicted in Fig. 2.

Detection and quantitation

The signal color on the test strips can be detected visually. For quantitation of the signal intensity, grayscale densitometry can be used. The test strips were scanned using an Expresstion 636 color image scanner (Epson, Torrance, CA), and the scanned images were converted into grayscale readings. The intensity of each signal was quantified with Scan Analysis densitometry software (Biosoft, Ferguson, MO)

\section{Results and discussion}

\section{Preparation and characterization of GT1b-liposomes}

Following repetitive freeze-thaw cycles, the GT1b-incorporated liposomes, encapsulating SRB, were prepared by the extrusion method. To decide the optimal amount of GT1b, several batches of liposomes were prepared with different amounts of GT1b in the lipid mixture, and the binding of BT to those liposomes was compared. The highest binding was observed when GT1b was approximately 1-2 mol\% of the total lipids in the lipid mixture (data not shown). Higher concentrations of GT1b made the liposomes unstable because of the large carbohydrate moiety. Therefore, to achieve the highest stability, the concentration of GT1b was maintained at less than 2 mol\% of total lipids in the lipid mixture. The DMB assay showed that about $40 \%$ of the GT1b in the lipid mixture was incorporated into the resulting liposomes.

The characteristics of the liposomes used in these studies are shown in Table 1. The mean diameter of GT1b-liposomes was measured by a particle-size analyzer to be $197 \mathrm{~nm}$. This result seems reasonable because the lipo-
Table 1 Characteristics of GT1b-liposomes

\begin{tabular}{|c|c|}
\hline Parameter & Value \\
\hline Mean diameter (nm) & $197 \pm 33$ \\
\hline Volume $(\mu \mathrm{L})$ & $4.0 \times 10^{-12}$ \\
\hline Liposome concentration (liposomes $\mathrm{mL}^{-1}$ ) & $5.3 \times 10^{11}$ \\
\hline SRB concentration $(\mathrm{mM})$ & 150 \\
\hline Number of SRB per liposome (molecules liposome ${ }^{-1}$ ) & $3.2 \times 10^{5}$ \\
\hline Number of GT1b per liposome (molecules liposome ${ }^{-1}$ ) & $2.1 \times 10^{4}$ \\
\hline
\end{tabular}

somes were extruded through $0.2-\mu \mathrm{m}$ pore size PC membrane filter and, without any sonication during preparation, the size of liposomes are only affected by the pore size of the membrane filter used during the extrusion [22]. With the assumption that the thickness of the bilayer is $4 \mathrm{~nm}$ [23], the internal volume of a single liposome can be calculated from the diameter. From the diameter of a liposome, the lipid concentration, and the concentration of encapsulated SRB, all other characteristics could be calculated as described previously [21]. The mean diameter, volume, and SRB content of a single GT1b-liposome molecule were comparable to those of liposomes prepared for previous studies of liposomal test strip assay [24]. The number of ganglioside molecules on the liposome surface, $2.1 \times 10^{4}$, was similar to the number of $1.9 \times 10^{4}$, reported by Singh et al. [9]. The stability of the liposomes was determined by measuring the fluorescence of SRB that leaked out of the liposomes during storage, and no significant changes in liposome stability were observed over 9 months of storage at $4^{\circ} \mathrm{C}$ in the dark. All buffers used in the liposome preparation and the assay were adjusted to have the same osmolarity as the encapsulated SRB, in order to prevent osmotic pressure-related swelling or crenation.

\section{Development of the test strip assay for BT detection}

The test strip assay format used in this study is depicted in Fig. 2. The assay is based on the strong binding between the sample BT and GT1b on the liposome surface, capillary migration on a nitrocellulose strip, and detection of the captured BT-liposome complex in an analytical zone. To minimize the nonspecific binding of GT1b-liposomes to the test strip, the NC membrane was treated with a blocking solution containing PVP. Of the blocking agents tested, PVP, bovine serum albumin (BSA), and gelatin showed consistently low backgrounds (data not shown). However, in the test strips blocked with BSA and gelatin, the reaction mixture appeared to migrate more slowly. Since the objective of this study was to develop a rapid detection method, PVP was chosen as the blocking reagent, with only a small amount $(0.01 \%)$ of gelatin added. Tween-20 was also added to the blocking solution for uniform migration of liposomes, but its concentration was only $0.002 \%$ to avoid the lysis of the liposomes.

In the assay, BT in the sample binds strongly and specifically to GT1b on the liposomes to form BT-GT1bliposome complexes that can migrate through the $\mathrm{NC}$ test 


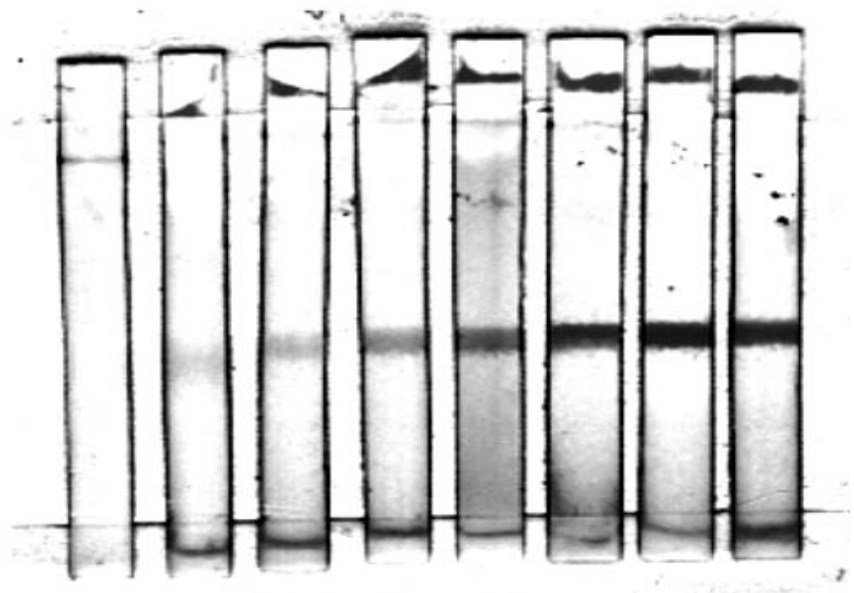

$\begin{array}{llllllll}A & B & C & D & \text { E } & F^{-} & G & H\end{array}$

Fig. 3 Scanned images of representative nitrocellulose test strips. Strips were run at room temperature, as described in "Materials and methods". Each strip was inserted into the test tube containing $100 \mu \mathrm{L}$ of the reaction mixture of GT1b-liposomes and BT at the indicated concentrations: $A$ negative control, $B 1 \times 10^{-5} \mu \mathrm{g} \mathrm{mL}^{-1}$, $C 1 \times 10^{-4} \mu \mathrm{g} \mathrm{mL}^{-1}, D 1 \times 10^{-3} \mu \mathrm{g} \mathrm{mL}^{-1}, E 1 \times 10^{-2} \mu \mathrm{g} \mathrm{mL}^{-1}, F \quad 1 \times$ $10^{-1} \mu \mathrm{g} \mathrm{mL}^{-1}, G 1 \mu \mathrm{g} \mathrm{mL}-1, H 10 \mu \mathrm{g} \mathrm{mL}^{-1}$

strip by capillary action. These complexes are then captured by immobilized anti-BT antibodies in the analytical zone of the strips and can be observed as a colored band in this zone due to the SRB encapsulated inside the transparent liposomes. The appearance of the actual test strips showing the colored bands due to different concentrations of BT is illustrated in Fig. 3. With various concentrations of BT $\left(0-10 \mu \mathrm{g} \mathrm{mL}^{-1}\right)$ in buffer, the intensity of the SRB signal in the analytical zone can be visually detected. The intensity of the band is proportional to the amount of toxin in the sample, and the visual detection limit for BT is approximately $100 \mathrm{pg} \mathrm{mL}^{-1}$.

The analytical sensitivity and detection limit of the test strip assay for BT detection was determined from a doseresponse curve (Fig. 4). Dose-response data were obtained by scanning densitometry of the test strips, which were run in various concentrations of BT. The limit of detection (LOD) is defined as the lowest concentration of toxin producing a signal intensity 3 times higher than the standard deviation of the intensity of the sample without toxin (i.e., the negative control). By this definition, the instrumental (densitometry) LOD of the current assay for BT is estimated to be $15 \mathrm{pg} \mathrm{mL}^{-1}$, which is about $3 \mathrm{mLD}_{50}$ (mouse 50\% lethal dose). The visual detection limit is about a factor of 10 higher. In the dose-response curve for BT, the intensity of the binding signal increases with increasing concentration of BT in the sample, providing a dynamic analytical range between approximately $10^{1}$ and $10^{6} \mathrm{pg} \mathrm{mL}^{-1}$, or about 5 orders of magnitude. Several research groups reported that their detection assays for biological toxins, including BT, utilizing ganglioside-liposomes showed high sensitivity $[8,9,25]$. However, these assays detected the color change due to conformational change in the liposomes [8] or the signal from dye-mark-

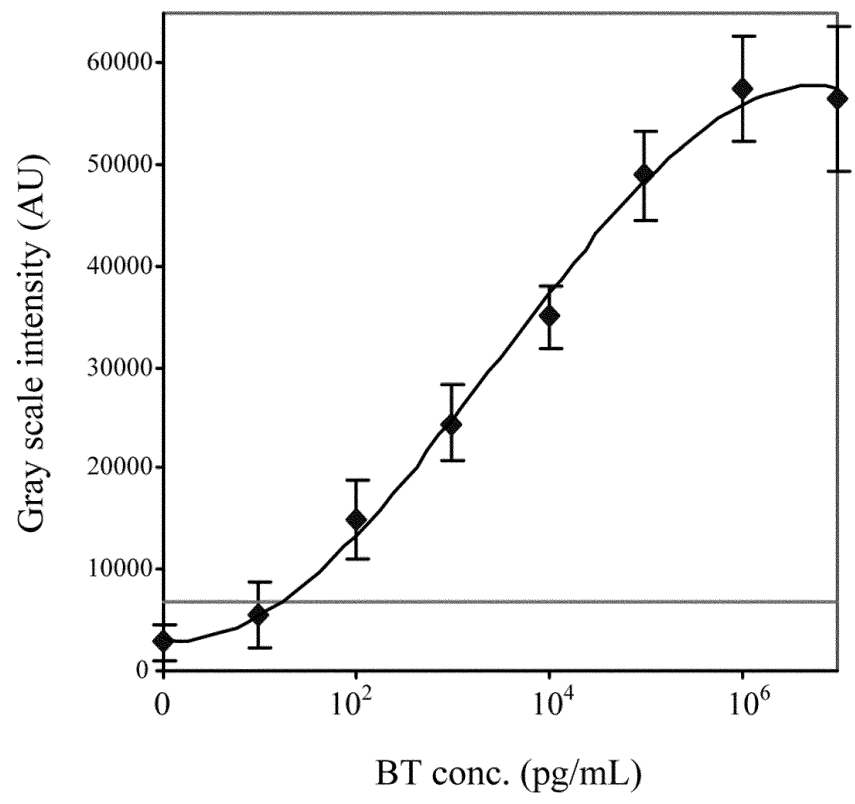

Fig. 4 Dose-response curve for botulinum neurotoxin, generated from test strip assays using GT1b-liposomes. The solid line represents the third-order polynomial curve fit, with an $R^{2}$ value of 0.996. The straight horizontal line indicates the limit of detection, defined as the color intensity 3 times higher than the standard deviation of the background (negative control) signal. Each point represents four replicates of grayscale values in the analytical zone

Table 2 Sensitivity of various detection assays for botulinum neurotoxin $^{\mathrm{a}}$

\begin{tabular}{|c|c|c|c|}
\hline Method & $\begin{array}{l}\text { LOD of } \\
\text { toxin type } A \\
\left(\mathrm{mLD}_{50}\right)^{\mathrm{b}}\end{array}$ & $\begin{array}{l}\text { Assay } \\
\text { time }\end{array}$ & $\begin{array}{l}\text { Refer- } \\
\text { ence }\end{array}$ \\
\hline Mouse bioassay & $1-2$ & 3-4 days & {$[32]$} \\
\hline RPHA & $1.3-1.6$ & $5-6 h$ & [33] \\
\hline \multirow[t]{4}{*}{ ELISA } & & $1-5 \mathrm{~h}$ & \\
\hline & 2 & & [34] \\
\hline & 9 & & [35] \\
\hline & $1-2$ & & [15] \\
\hline ELCA & $<1$ & $>18 \mathrm{~h}^{\mathrm{c}}$ & [27] \\
\hline Enzymatic assay ${ }^{d}$ & 0.5 & $5-6 h$ & [16] \\
\hline This study & 3 & $20 \mathrm{~min}$ & \\
\hline
\end{tabular}

aAbbreviations: $\mathrm{mLD}_{50}$, mouse $50 \%$ lethal dose; RPHA, reversed passive hemagglutination; ELISA, enzyme-linked immunosorbent assay, ELCA, enzyme-linked coagulation assay

${ }^{\mathrm{b}} 1 \mathrm{mLD}_{50}$ for chromatographically purified type A botulinum neurotoxin has been calculated as approximately $6 \mathrm{pg} \mathrm{mL}^{-1}$ [32]. At $1 \mathrm{mLD}_{50}, 50 \%$ of mice injected with $1 \mathrm{~mL}$ will die

'Including the immunobinding phase

dPerformed with botulinum neurotoxin type B

ers or enzymes on the liposome surface $[9,25]$. In this study, we used dye-encapsulating liposomes, which, because of the much larger number of dye molecules contained in each liposome, produced a much higher signal intensity, thereby resulting in higher sensitivity. The LOD of $3 \mathrm{mLD}_{50}$ is comparable to the most sensitive BT detection assays previously reported $[15,16,26,27]$ for which the detection limits reach the level of the mouse bioassay. 
These previously reported assays, based on ELISA or the enzymatic activity of BT, are time-consuming and need to be performed by well-trained personnel. In contrast, the assay developed in this study can be completed within $20 \mathrm{~min}$ and is very easy to perform. Therefore, this result suggests a BT detection assay using GT1b-liposomes can replace existing methods. In Table 2, the GT1b-liposome assay is compared to other previously reported BT detection assays.

Comparison of the sensitivity of GT1b-liposomes to immunoliposomes for BT detection

The sensitivity of the BT detection assay using GT1b-liposomes was compared to immunoliposomes with antibodies to BT on the liposome surface (Fig. 5). The LOD for BT in the immunoliposome assay system was estimated from the dose-response curve to be $40 \mathrm{pg} \mathrm{mL}^{-1}$. At concentrations equal to or higher than $100 \mathrm{pg} \mathrm{mL}^{-1}$, the signal could be visually detected. This result suggests that the binding of the ganglioside to the toxin is as strong and specific as the binding of antibodies to the toxin. The sensitivity of the immunoliposome assay system is slightly lower, the detection limit a little higher ( $\mathrm{LOD}=40 \mathrm{pg} \mathrm{mL}^{-1}$ versus $15 \mathrm{pg} \mathrm{mL}^{-1}$ ), and the signal intensity decreased more at higher concentrations of toxin as compared to the GT1b-liposome assay system. This poorer performance of

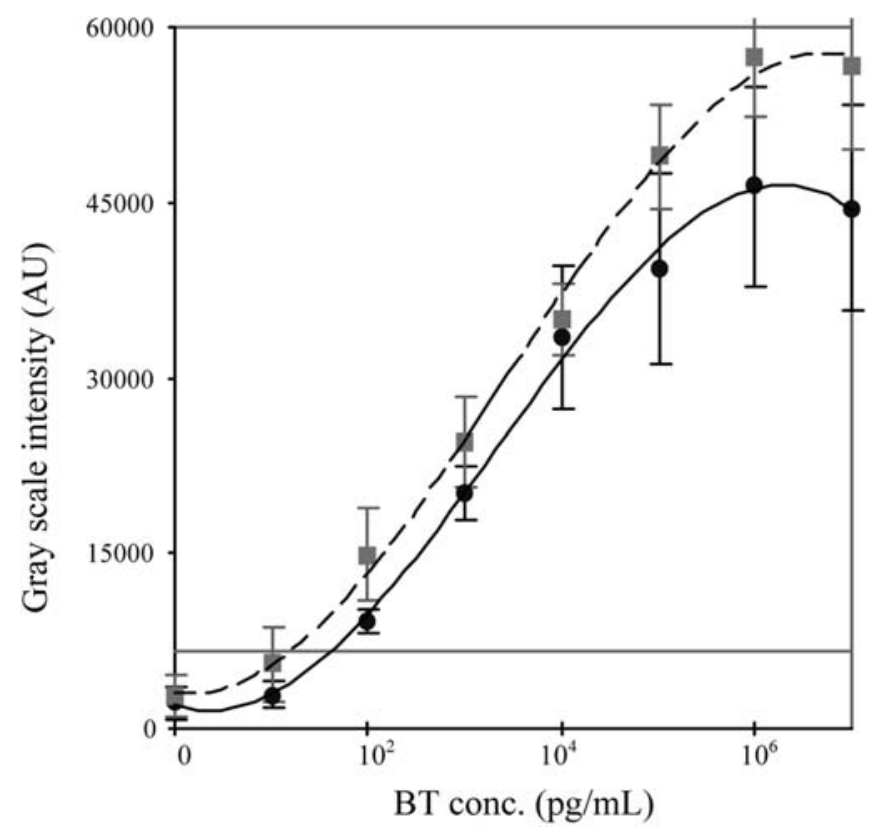

Fig. 5 Comparison of the dose-response curves for immunoliposomes (O) with GT1b-liposomes ( $\boldsymbol{\square})$ for botulinum neurotoxin detection. The solid line represents the curve fit for immunoliposomes, and the dashed line represents the curve fit for GT1b-liposomes (as shown in Fig. 4), with $R^{2}$ values of 0.997 and 0.996, respectively. The straight horizontal line indicates the limit of detection for the immunoliposomes, defined as the color intensity 3 times higher than the standard deviation of the background (negative control) signal. Each point represents four replicates of grayscale values in the analytical zone the immunoliposome assay can possibly be explained by the format used in this study. In the sandwich assay format of the immunoliposome assay, the same antibodies were used for coating the analytical zone on test strips and for conjugation onto the liposome surface. This would result in these antibodies competing for the same epitopes on the toxin, which could ultimately lead to the lower sensitivity of the assay. This problem could possibly be mitigated by using antibodies to two different BT epitopes, one for use on the test strip analytical zone and the other for conjugation to liposomes. However, considering the complex and time-consuming (at least 2 days) process required to prepare immunoliposomes, ganglioside-liposomes have a distinct advantage over immunoliposomes in their ease of preparation.

Specificity of a capillary migration test strip assay for BT detection

To evaluate the specificity of the test strip assay for BT, the assay was performed substituting various other ganglioside-binding toxins for BT. For this purpose, cholera toxin (CT) from Vibrio cholerae, diphtheria toxin (DT) from Corynebacterium diphtheriae, E. coli heat-stable toxin (STa), and tetanus toxin (TT) from Clostridium tetani were used. For safety purposes, commercially available toxoids or subunits of toxin were used in this study, except for STa. Each toxin was added to the assay system at high concentration $\left(10 \mu \mathrm{g} \mathrm{mL}^{-1}\right)$, and the signal intensity was measured, as described in "Materials and methods". As shown in Fig. 6, the BT detection assay using GT1b-liposomes showed a high signal intensity for BT over the

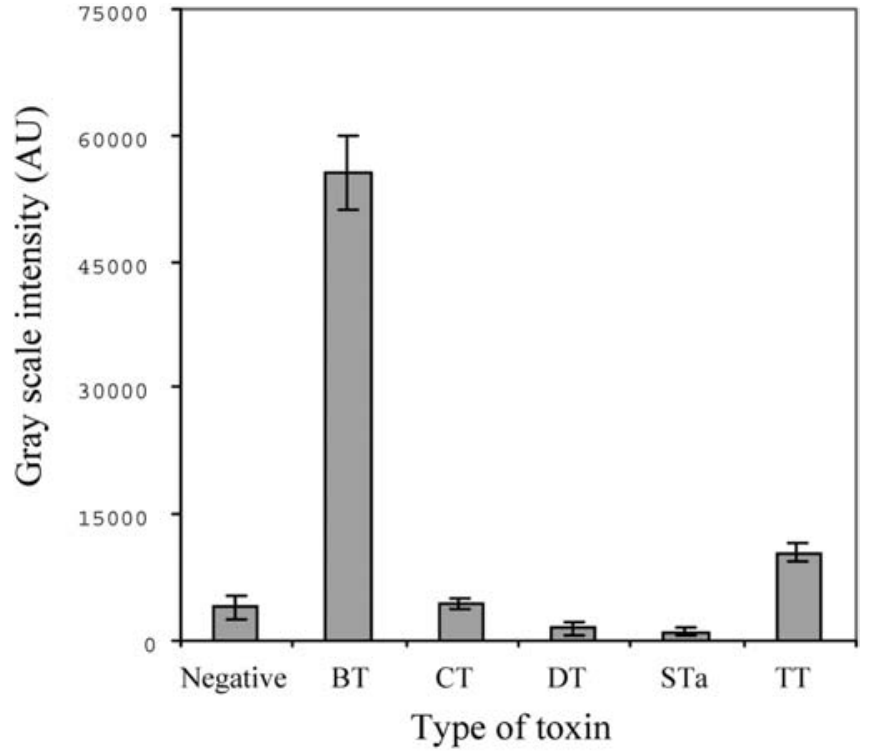

Fig. 6 Specificity of the BT detection assay using GT1b-liposomes. A $10 \mu \mathrm{g} \mathrm{mL}^{-1}$ aliquot of each toxin was dissolved in TBS and used in the assay. The data shown are an average of 3 replicates. Abbreviations: BT, botulinum toxin; CT, cholera toxin; DT, diphtheria toxin; STa, E. coli heat-stable toxin; TT, tetanus toxin 
other toxins, which suggests specificity of the assay for BT detection. In this experiment, TT showed a little higher binding signal than the other toxins and this could be the result of the similarity of TT and BT in terms of structure and amino acid sequence [28, 29]. In addition, it has been reported that tetanus toxin binds to gangliosides, specifically to the disialoganglioside GD1b and GT1b, as membrane receptors $[30,31]$. Despite the fact that TT in the sample can also bind to GT1b on the liposomes, the result from this study suggests that the antibodies to BT, immobilized on the test strip, can provide enough specificity to distinguish BT from TT. The high specificity of the detection assay, which requires binding to two separate and distinct receptors, provides an advantage over other immunological detection methods, which show the problems of false-positive signals from cross-reactivity, especially in sandwich-type assays.

\section{Conclusions}

In this study, GT1b-liposomes were used in a sandwich test strip assay for botulinum neurotoxin detection. We demonstrated that GT1b-liposomes can interact with BT at least as strongly as immunoliposomes. The assay developed in this study provides detection levels comparable to the mouse bioassay and most of the other previously reported assays, but has the added advantages of simplicity and rapidity. These results show that a capillary migration test strip assay can be an alternative assay system for BT detection, which can also be applied to the field screening of food or environmental samples. This assay system could be applied to the detection of other biological toxins that use gangliosides as their cell receptors. However, for the application of this assay to field screening, the effect of food matrices will be evaluated. Preliminary studies on a variety of vegetable and seafood samples have demonstrated only a moderate loss in sensitivity with the exception of certain fish, such as salmon, that are very high in fatty acids that appear to interfere with liposome integrity. Also, the effect of other organisms present in the sample on the sensitivity of this assay will be studied.

Acknowledgments The authors acknowledge partial support for this research from Innovative Biotechnologies International, Inc., Grand Island, NY, and the Cornell University Center for Biotechnology, a New York State Center for Advanced Technology of the New York State Office of Science, Technology, and Academic Research, under whose auspices this publication was developed. This research also was supported in part by the Cornell University Agricultural Experiment Station Federal Formula Funds, Project No. NYG 623498, received from Cooperative State Research, Education, and Extension Service, US Department of Agriculture. Any opinions, finding, conclusions, or recommendations expressed in this publication are those of the authors and do not necessarily reflect the view of the US Department of Agriculture.

\section{References}

1. Eidels L, Proia RL, Hart DA (1983) Membrane receptors for bacterial toxins. Microbial Rev 47:596-620

2. Holmgren J, Elwig H, Fredman P, Strannegard O, Svennerholm L (1980) Gangliosides as receptors for bacterial toxins and Sendai virus. Adv Exp Med Biol 125:453-470

3. Fishman PH, Pacuszke T, Orlandi PA (1993) Gangliosides as receptors for bacterial enterotoxins. Adv Lipid Res 25:165-187

4. Van Heyningen WE, Carpenter CC, Pierce NF, Greenough WB III (1971) Deactivation of cholera toxin by ganglioside. J Infect Dis 124:415-418

5. Kitamura M, Iwamori M, Nagai Y (1980) Interaction between Clostridium botulinum neurotoxin and gangliosides. Biochim Biophys Acta 628:328-335

6. Ledley FD, Lee G, Kohn LD, Habig WH, Hardgree MC (1977) Tetanus toxin interactions with thyroid plasma membranes. Implications for structure and function of tetanus toxin receptors and potential pathophysiological significance. J Biol Chem 252:4049-4055

7. Fishman PH (1982) Role of membrane gangliosides in the binding and action of bacterial toxins. J Membr Biol 69:85-97

8. Pan JJ, Charych D (1997) Molecular recognition and colorimetric detection of cholera toxin by poly(diacetylene)liposomes incorporating $\mathrm{G}_{\mathrm{m} 1}$ ganglioside. Langmuir 13:1365-1367

9. Singh AK, Harrison SH, Schoeniger JS (2000) Gangliosides as receptors for biological toxins: development of sensitive fluoroimmunoassays using ganglioside-bearing liposomes. Anal Chem 72:6019-6024

10. Ahn-Yoon S, DeCory T, Baeumner AJ, Durst RA (2003) Ganglioside-liposome immunoassay for the ultrasensitive detection of cholera toxin. Anal Chem 75:2256-2261

11. Lasic DD, Papahadjopoulos D (1995) Liposomes revisited. Science 267:1275-1276

12. Arnon SS, Schechter R, Inglesby TV, Henderson DA, Bartlett JG, Ascher MS, Eitzen E, Fine AD, Hauer J, Layton M, Lillibridge S, Osterholm MT, O'Toole T, Parker G, Pearl TM, Russell PK, Swerdlow DL, Tonat K (2001) Botulinum toxin as a biological weapon: medical and public health management. JAMA 285:1059-1070

13. Kautter DA, Solomon HM (1976) Collaborative study of a method for the detection of $\mathrm{Cl}$. botulinum and its toxins in foods. J Assoc Anal Chem 60:541-545

14. Hatheway CL, Ferreira JL (1996) Detection and identification of Clostridium botulinum neurotoxins. Adv Exp Med Biol 391: 481-498

15. Ekong TAN, McLellan K, Sesardic D (1995) Immunological detection of Clostridium botulinum toxin type A in therapeutic preparations. J Immunol Methods 180:181-191

16. Wictome M, Newton KA, Jameson K, Dunnigan P, Clarke S, Gaze J, Tauk A, Foster KA, Shone CC (1999) Novel assays for the detection of botulinum toxins in foods. Dev Biol Stand 101:141-145

17. Szabo ZA, Pemberton JM, DesMarchelier PM (1993) Detection of the genes encoding botulinum neurotoxin types $A$ to $\mathrm{E}$ by the polymerase chain reaction. Appl Environ Microbiol 59: 3011-3020

18. Mayer LD, Hope MJ, Cullis PR (1986) Vesicles of variable sizes produced by a rapid extrusion procedure. Biochim Biophys Acta 858:161-168

19. Bartlett GR (1959) Phosphorus assay in column chromatography. J Biol Chem 234:466-468

20. Hikita T, Tadano-Aritomi K, Iida-Tanaka N, Toyoda H, Suzuki A, Toida T, Imanari T, Abe T, Yanagawa Y, Ishizuka I (2000) Determination of N-acetyl- and N-glycolylneuraminic acids in gangliosides by combination of neuraminidase hydrolysis and fluorometric high-performance liquid chromatography using a GM3 derivative as an internal standard. Anal Biochem 281: 193-201 
21. Siebert STA, Reeves SG, Durst RA (1993) Liposome immunomigration field assay device for Alachlor determination. Anal Chim Acta 282:297-305

22. Szoka F Olson F, Heath T, Vail W, Mayhew E (1980) Preparation of unilamellar liposomes of intermediate size $(0.1-0.2 \mu \mathrm{m})$ by a combination of reverse phase evaporation and extrusions through polycarbonate membranes. Biochim Biophys Acta 601:559-571

23. Israelachvili J N, Mitchell DJ (1975) A model for the packing of lipids in bilayer membranes. Biochim Biophys Acta 389: 13-19

24. Park S, Durst RA (2000) Immunoliposome sandwich assay for the detection of Escherichia coli O157:H7. Anal Biochem 280: $151-158$

25. Alfonta L, Willner I, Throckmorton DJ, Singh AK (2001) Electrochemical and quartz crystal microbalance detection of the cholera toxin employing horseradish peroxidase and GM1functionalized liposomes. Anal Chem 73:5287-5295

26. Shone C, Wilson-Smith P, Appleton N, Hambleton P, Modi N, Gatley S, Melling J (1985) Monoclonal antibody-based immunoassay for type A Clostridium botulinum toxin is comparable to the mouse bioassay. Appl Environ Microbiol 50:63-67

27. Doellgast G, Triscott MX, Beard GA, Bottoms JD, Cheng T, Roh BH, Roman MG, Hall PA, Brown JE (1993) Sensitive enzyme-linked immunosorbent assay for detection of Clostridium botulinum neurotoxins $\mathrm{A}, \mathrm{B}$, and $\mathrm{E}$ using signal amplication via enzyme-linked coagulation assay. J Clin Microbiol 31:24022409
28. Sathyamoorthy V, DasGupta BR (1985) Partial amino acid sequence of the heavy and light chains of botulinum neurotoxin type E. Biochem Biophys Res Commun 127:768-772

29. Halpern JL, Smith LA, Seamon KB, Groover KA, Habig WH (1989) Sequence homology between tetanus and botulinum toxins detected by an antipeptide antibody. Infect Immun 57: $18-22$

30. Van Heyningen WE (1974) Gangliosides as membrane receptors for tetanus toxin, cholera toxin and serotonin. Nature 249:415-417

31. Helting TB, Zwisler O, Wiegandt H (1977) Structure of tetanus toxin II. Toxin binding to ganglioside. J Biol Chem 252:194198

32. Schantz EJ, Kautter DA (1978) Standardized assay for Clostridium botulinum toxins. J Assoc Off Anal Chem 61:9699

33. Johnson HM, Brenner K, Angelotti R, Hall HE (1966) Serological studies of types A, B, and E botulinal toxins by passive hemagglutination and betonite flocculation. J Bacteriol 91: 967-973

34. Ransom GM, Lee WH, Elliot EL, Lattuada CP (1993) In: DasGupta BR (ed) Enzyme-linked immunosorbent assays (ELISAs) to detect botulinum toxins using high titer rabbit antisera in Botulinum and Tetanus Neurotoxins. Plenum Press, New York, pp 449-461

35. Potter MD, Meng J, Kimsey P (1993) An ELISA for detection of botulinal toxin types $\mathrm{A}, \mathrm{B}$, and $\mathrm{E}$ in inoculated food samples. J Food Protect 56:856-861 